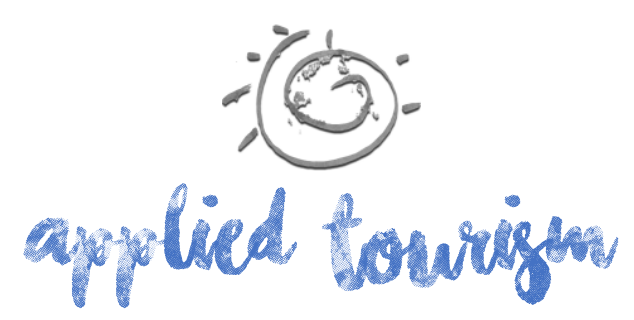

Volume 2, número 3, 2017, p. 65-78

\title{
ATIVIDADES RECREATIVAS E LÚDICAS: um estudo nas escolas estaduais da cidade de Santa Vitória do Palmar, RS - Brasil
}

\author{
Alex Borges Dias \\ Bacharelando em Turismo \\ Universidade Federal do Rio Grande \\ academicoalex@hotmail.com \\ Leticia Indart Franzen \\ Doutoranda em Turismo e Hospitalidade (UCS) \\ Docente na Universidade Federal do Rio Grande \\ leticiaifranzen@gmail.com \\ Viviane Rocha Teixeira \\ Bacharelanda em Turismo \\ Universidade Federal do Rio Grande \\ vivih_rocha.18@hotmail.com
}

Recebido: 28 de junho, 2017

Aprovado: 27 de outubro, 2017

\section{RESUMO}

Os processos educativos são fundamentais para a formação de cidadãos mais conscientes de seu papel na construção de uma sociedade mais justa e igualitária. Em um mundo onde as atividades humanas são constantemente aceleradas pelas práticas capitalistas, se torna cada vez mais necessário pensar o papel da educação na formação de novos cidadãos conscientes de sua importância na sociedade. Desse modo, este trabalho teve por objetivo identificar as atividades recreativas e lúdicas que contribuem nos processos educativos dos alunos do $1^{\circ}$ ano das escolas estaduais em Santa Vitória do Palmar, RS - Brasil. Na metodologia foi feita uma pesquisa bibliográfica. Para a coleta de dados foram feitas entrevistas com os professores responsáveis pelas turmas do primeiro ano de cada escola e foi utilizado o método de observação não-participante, além do levantamento fotográfico. Identificou-se que todas as escolas estaduais da cidade possuem atividades recreativas e lúdicas que contribuem para os processos educativos dos alunos matriculados.

Palavras-chaves: Recreação. Ludicidade. Escola. Santa Vitória do Palmar/RS. 


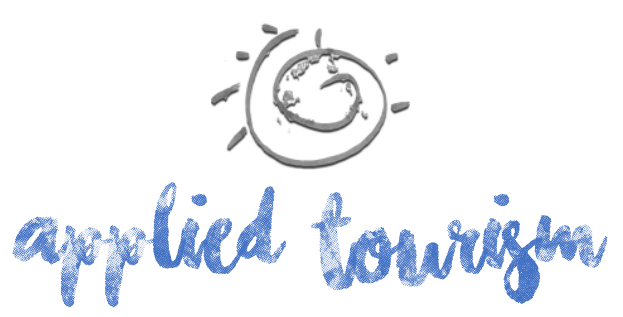

Volume 2, número 3, 2017, p. 65-78

\section{INTRODUÇÃO}

A prática do lazer é um tema bastante discutido por vários autores de diversas áreas do conhecimento, em alguns casos cada um possui concepções diferentes sobre o assunto. Um dos conceitos que teve mais destaque no Brasil, segundo os autores Gomes, Pinheiro e Lacerda (2010), foi o conceito surgido na década de 70 pelo sociólogo francês Dumazedier. O conceito de Dumazedier sobre o lazer contribuiu para o melhor entendimento sobre desenvolvimento desta prática.

Neste contexto, Dumazedier (2008 \& 2014) expôs que o lazer está explícito em diversas formas de ocupação do tempo, sendo aquelas em que o ser humano se entrega de livre vontade, seja para a prática do repouso, recreação, diversão, participar de ações sociais voluntárias, atividades sempre realizadas após o cumprimento das obrigações profissionais, familiares e sociais.

A prática de atividades de lazer possui uma função importante, pois faz com que o ser humano se desvincule da rotina diária, mesmo que por um curto período tempo, sendo possível experimentar sensações e expor sentimentos e emoções (Dumazedier, 2008 \& 2014).

Moletta (2003), ainda aborda que o lazer proporciona aos seres humanos, independentemente de sua faixa etária, classe e, estilos sociais, uma melhor qualidade de vida, estimula a saúde mental e faz com que as relações de convívio social sejam mais prazerosas.

Segundo Dumazedier (2008) o lazer como é entendido hoje é fruto de um processo que começou a ser construído após o início da primeira Revolução Industrial. Antes disso o tempo de trabalho e não-trabalho aconteciam de forma natural e simultânea. O trabalho acontecia de forma a contemplar os ciclos da natureza e este ritmo era cortado diversas vezes por pausas para jogos, cerimônias, cantos e, em geral, se confundiam com as 


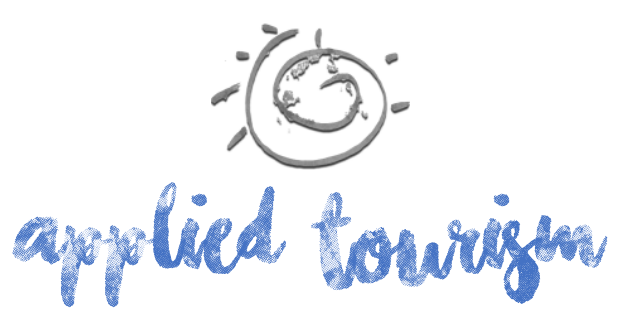

Volume 2, número 3, 2017, p. 65-78

Desse modo, as atividades de lazer, se bem planejadas, contribuem de forma eficaz com os processos educativos dos alunos para o fortalecimento de valores sociais e individuais de forma recreativa, descontraída e que podem influenciar positivamente na vida social do indivíduo.

As atividades informais, no âmbito das escolas, são aquelas atividades livres da obrigatoriedade por parte dos alunos e que proporcionam maior sensação de livre escolha podendo oportunizar uma forma diferenciada de aprendizado.

O lazer, de acordo com os já clássicos estudiosos do assunto, como Dumazedier (2008 \& 2014) implica a liberação e o prazer, o descanso, o divertimento e o desenvolvimento. No contexto escolar, essas atividades de lazer proporcionam, entre tantos, o desenvolvimento da personalidade. Dumazedier (2014, p. 33 e 34) apresenta conceitos que precisam ser revisitados, principalmente ao mencionar que o lazer

[...] permite uma participação social maior e mais livre, [...] oferece novas possibilidades de integração voluntária de agrupamentos recreativos, culturais e sociais; possibilita o desenvolvimento livre de atitudes adquiridas na escola [...]. A função de desenvolvimento pode ainda criar novas formas de aprendizagem (learning) voluntária, a serem praticadas durante a vida e contribuir para o surgimento de condutas inovadoras e criadoras.

Segundo Waichman (1997), a recreação pode ser definida como a educação em e do (ou para) o tempo livre e funciona como um subsistema da educação não-formal que supõe uma estrutura, métodos específicos, objetivos precisos, docentes especializados no assunto, etc. partindo de um contínuo mais consumista e chegando a situação de protagonista.

A racionalidade sensível é um desafio à análise objetivista da ciência, à argumentação lógica, ao utilitarismo técnico, pois o conhecimento sensível opera pela incerteza, pela imprevisibilidade, está aberto à configuração de novas possibilidades de construção da realidade. Nesse contexto, o lúdico pode ser compreendido como um operador da imaginação, do sonho e da criatividade como dimensões do humano. (Melo \& Dias, 2010 p. 3). 


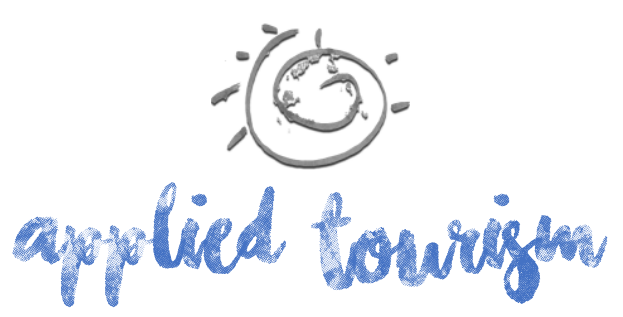

Volume 2, número 3, 2017, p. 65-78

dos estudantes, visto que, estas atividades fazem papel de mediação entre a aprendizagem na escola e a reprodução destas experiências na vida cotidiana dos estudantes. Porém, se fez necessária a sensibilização por parte da família para estas questões.

\section{METODOLOGIA}

Esta pesquisa, segundo seus fins e objetivos, caracteriza-se por ser do tipo exploratória, como forma de obtenção de informações teóricas e conceituais sobre os temas principais desta análise, utilizando-se do levantamento bibliográfico e documental. A pesquisa exploratória tem como objetivo proporcionar uma aproximação entre o pesquisador e as discussões que já foram feitas sobre os temas abordados nesta pesquisa (Leal, 2011).

Para entender melhor e aproximar-se mais do objeto de estudo, a pesquisa de campo se fez necessária, possibilitando uma experiência direta com alunos das escolas estudadas, objeto de estudo desta pesquisa, e permitindo que os pesquisadores pudessem observar os alunos dessas escolas (Gil, 2010).

Este trabalho caracterizou-se como um estudo descritivo de caráter qualitativo com entrevistas feitas com os professores que fazem utilização de técnicas informais de aprendizagem, com atividades lúdicas e recreativas. As entrevistas foram realizadas no mês de outubro de 2016 aos professores responsáveis pelas turmas de $1^{\circ}$ ano dos colégios estaduais de Santa Vitória do Palmar.

Também foi utilizado o método de observação não-participante e um levantamento fotográfico com o intuito de identificar e registrar o momento em que as atividades eram realizadas pelos alunos. Os professores e diretores das escolas não autorizaram a realização de entrevistas com as crianças. 


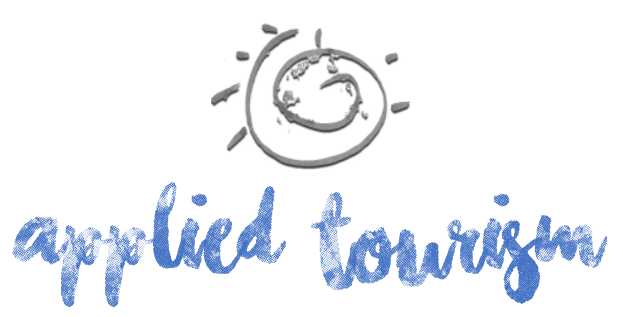

Volume 2, número 3, 2017, p. 65-78

Tabela 1 - Atividades informais das escolas estaduais de Santa Vitória do Palmar.

\begin{tabular}{|c|c|c|c|c|}
\hline ESCOLA & ATIVIDADES & & IDADE & QTD \\
\hline 1 & $\begin{array}{l}\text { Atividades de Recreação; } \\
\text { Jogos lúdicos em geral; } \\
\text { Passeios ao ar livre; } \\
\text { Visita a museus; } \\
\text { Desenho; }\end{array}$ & $\begin{array}{l}\text { Teatro; Dobraduras; } \\
\text { Montagem; Modelagem; } \\
\text { Dramatização; } \\
\text { Atividades físicas; }\end{array}$ & $\begin{array}{l}\text { Entre } 6 \\
\text { e } 7 \text { anos }\end{array}$ & 30 \\
\hline 2 & $\begin{array}{l}\text { Pintura; } \\
\text { Criação de mosaicos; } \\
\text { Dobraduras; } \\
\text { Corte e recorte; } \\
\text { Jogos lúdicos em geral, } \\
\text { música, piquenique; } \\
\end{array}$ & $\begin{array}{l}\text { Feiras; } \\
\text { Gincanas; } \\
\text { Desfiles; } \\
\text { Apresentação de talentos; } \\
\text { Teatro; } \\
\text { Método Alfabético Fônico; }\end{array}$ & $\begin{array}{l}\text { Entre } 6 \\
\text { e } 7 \text { anos }\end{array}$ & 15 \\
\hline 3 & $\begin{array}{l}\text { Atividades físicas de } \\
\text { recreação; } \\
\text { Filmes e vídeos; } \\
\text { Massa de modelar; } \\
\text { Cartazes; }\end{array}$ & $\begin{array}{l}\text { Ajudante do dia; } \\
\text { Jogos lúdicos em geral; } \\
\text { Corte e recorte; } \\
\text { Jogos de montar; }\end{array}$ & $\begin{array}{l}\text { Entre } 6 \\
\text { e } 7 \text { anos }\end{array}$ & 25 \\
\hline 4 & $\begin{array}{l}\text { Visita a museus; } \\
\text { Pintura; } \\
\text { Desenho; } \\
\text { Teatro; } \\
\text { Danças tradicionais; }\end{array}$ & $\begin{array}{l}\text { Hora do conto; } \\
\text { Vídeos, filmes; } \\
\text { Jogos de montagem; } \\
\text { Formação de palavras; }\end{array}$ & $\begin{array}{l}\text { Entre } 6 \\
\text { e } 7 \text { anos }\end{array}$ & 14 \\
\hline
\end{tabular}

Fonte: Elaborada pelos autores, 2016

Na figura 1 é possível verificar um dos momentos de recreação vivenciados pelas crianças

da Escola 1. Durante a observação, os pesquisadores identificaram que as crianças interagiram entre si, sem nenhum tipo de separação. 


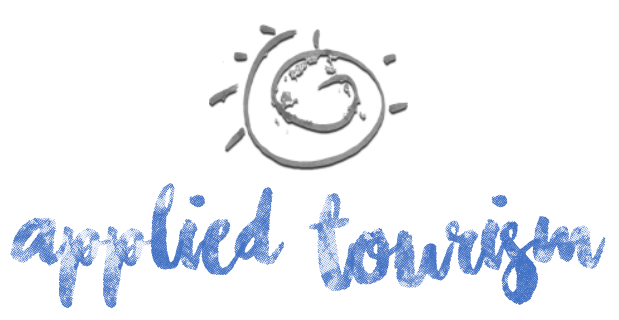

Volume 2, número 3, 2017, p. 65-78

Figura 1 - Atividade de recreação na Escola 1

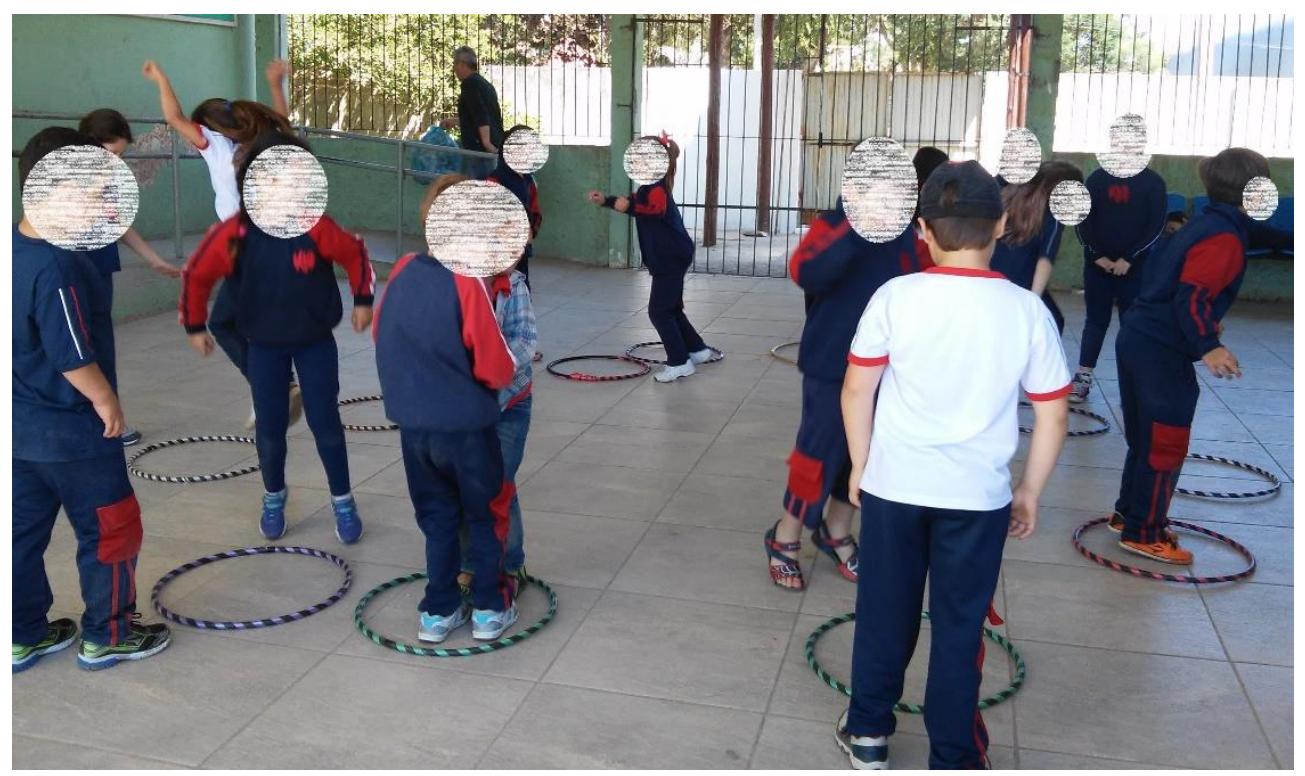

Fonte: Acervo dos autores, 2016.

No Colégio 2 foram identificadas tarefas de pintura, criação de mosaicos, dobradura, corte e recorte, jogos lúdicos, música, piquenique, feiras, gincanas, desfiles, apresentação de talentos, teatro e a utilização do método alfabético fônico. Na figura 2, a seguir, é possível observar as crianças fazendo desenhos de animais que participaram de uma história individual de cada aluno.

Figura 2 - Atividades lúdicas no Colégio 2

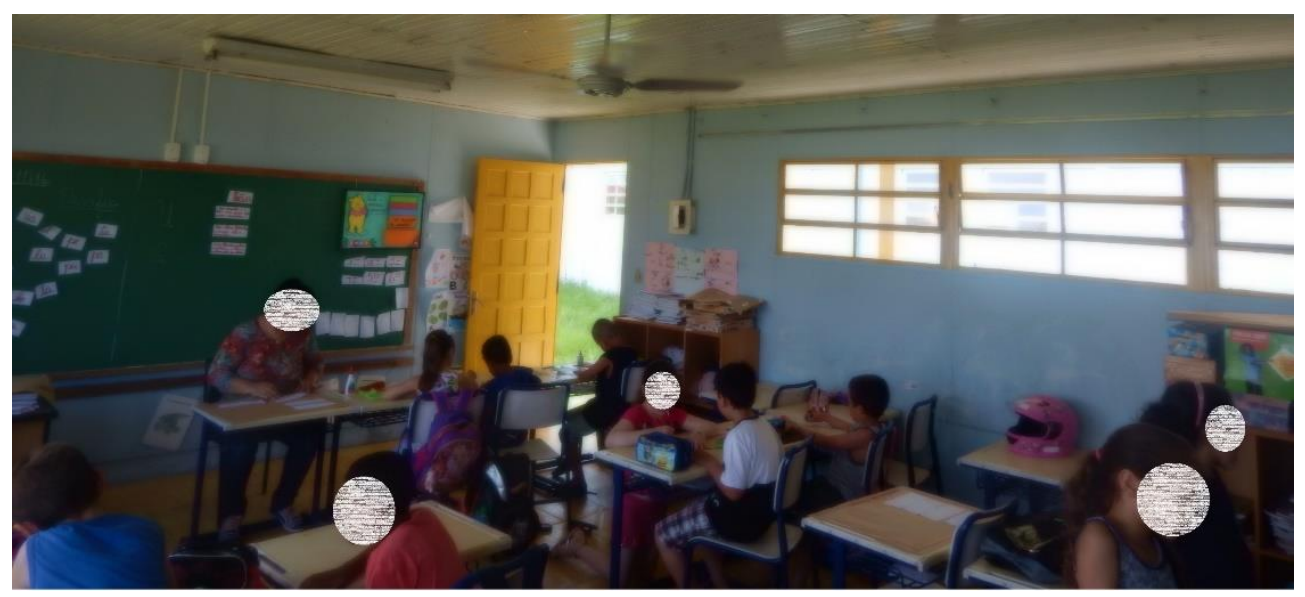

Fonte: Acervo dos autores, 2016. 


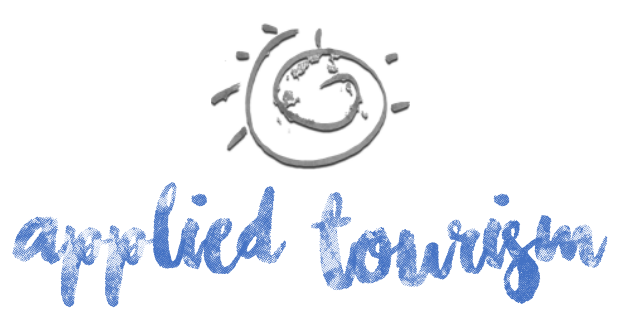

Volume 2, número 3, 2017, p. 65-78

$\mathrm{Na}$ Escola 3 foram identificadas atividades como visitas a museus, atividades de pintura, desenho, teatro, danças tradicionais regionais, a hora do conto, vídeos e filmes educativos, jogos de montagem de quebra-cabeça e jogos de formação de palavras. Na Escola 4 identificou-se atividades físicas, atividades de recreação, filmes e vídeos, atividades com massa de modelar, criação de cartazes ilustrativos, o ajudante do dia, jogos lúdicos, corte e recorte e jogos de montar partes.

\section{Percepção dos professores e diretores das instituições}

Quando questionadas sobre a forma como as atividades em sala são planejadas, de forma geral, todas as professoras responderam que quem planeja estas atividades são os professores de acordo com o conteúdo da aula. Durante a aula são realizadas várias atividades para evitar a distração e cansaço das crianças e tornar a aula descontraída. A recreação, passeios, filmes e outros são planejados juntamente com a direção das escolas. As professoras foram questionadas sobre o que as suas direções pensam a respeito do processo de aprendizagem dos alunos por meio das brincadeiras.

As quatro diretoras dizem que incentivam, ajudam e se preocupam em realizar estes tipos de atividades lúdicas com as crianças, pois entendem que essas atividades são importantes para um aprendizado mais completo e de qualidade. De acordo com os professores entrevistados, estas atividades informais são essenciais para um aprendizado de qualidade, pois contribuem com o desenvolvimento de habilidades interpessoais e intrapessoais dos alunos e constituem elementos importantíssimos de aprendizado na escola que devem ser levados a sério pelos professores, visto que crianças entre 6 e 7 anos assimilam melhor 0 conteúdo de uma maneira mais descontraída, com a forma lúdica de aprendizagem. 


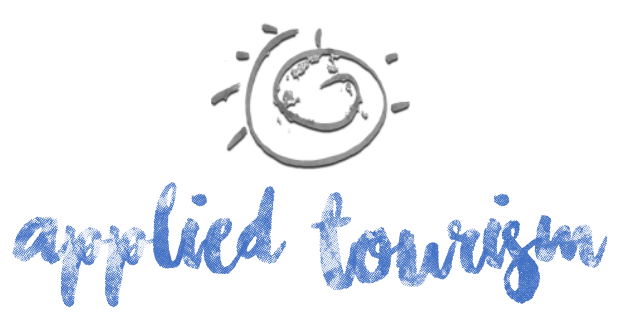

Volume 2, número 3, 2017, p. 65-78

\section{Aplicabilidade dos resultados}

Os resultados obtidos mostram que as quatro escolas estaduais presentes na cidade de Santa Vitória do Palmar desenvolveram o modelo lúdico de aprendizagem como reforço ao modelo tradicional institucionalizado. Essas escolas possuem diferenças entre si, tanto na metodologia desenvolvida para a elaboração das atividades, como na aplicação dessas atividades aos alunos.

Os resultados obtidos em cada escola contribuem para que seja desenvolvido um projeto de extensão vinculado às escolas estaduais da cidade de Santa Vitória do Palmar, que contará com o apoio da Universidade Federal do Rio Grande (FURG) na elaboração de atividades ligadas ao lazer e à educação de forma descontraída. O projeto terá como objetivo apoiar as escolas estaduais estudadas a desenvolver novas atividades lúdicas pautadas no lazer. Essas atividades terão como objetivo desenvolver as habilidades interpessoais e intrapessoais dos alunos do primeiro ano das escolas estaduais da cidade de Santa Vitória do Palmar.

O projeto que se pretende desenvolver contribuirá com as escolas estaduais do município ao apoiar os professores responsáveis pelas turmas de séries iniciais no desenvolvimento de atividades ligadas ao aprendizado formal. Desse modo o ensino formal será complementado e reforçado pelas atividades que serão executadas ao final de cada conteúdo apresentado aos alunos.

As atividades serão elaboradas em conjunto com os professores que já lecionam nessas escolas. Ao final de cada mês os responsáveis pelo projeto farão uma reunião com todos os professores responsáveis para discutir ideias e trocar informações. Desse modo, os professores poderão trocar informações entre si e aprimorar seus métodos de ensino não formal.

Essa pesquisa carece de aprofundamentos, o assunto não se esgota aqui. Novas pesquisas deverão ser desenvolvidas, incluindo os alunos, para que se possa perceber a evolução do 


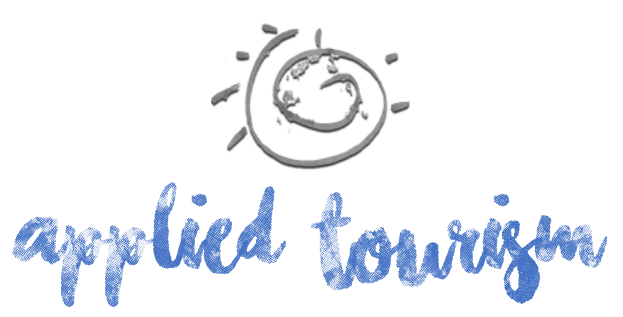

Volume 2, número 3, 2017, p. 65-78

aprendizado, bem como, a real diferença entre turmas que possuem atividades recreativas e turmas que não as realiza. Pretende-se incluir ou viabilizar viagens e/ou passeios turísticos como forma de recreação e aprendizagem.

\section{CONSIDERAÇÕES FINAIS}

As atividades informais de aprendizagem são elementos fundamentais do processo de ensino nas escolas, pois proporcionam ao aluno uma maneira divertida de aprender. Além de apreender o conteúdo ensinado em aula o aluno tem acesso ao desenvolvimento pleno de suas capacidades pessoais e de interação social. Nas Escolas 3 e 4 não foi possível fotografar as atividades, pois os professores responsáveis pelas turmas não autorizaram.

Conclui-se que as diversas atividades informais identificadas no ensino podem, também, serem utilizadas como forma de distração e, ao mesmo tempo, de aprendizagem para os alunos. Para estudos futuros sugere-se uma aproximação mais profunda com as atividades de sala de aula e a formulação do quadro de entrevistas a fim de coletar dados mais completos sobre as atividades junto dos alunos.

Sugere-se também a criação e o desenvolvimento de um projeto de extensão junto das escolas estaduais estudadas para desenvolver novas formas de aprendizagem ligadas a ludicidade e, com esta ação, tornar o ensino mais eficiente e contribuir também com a formação de cidadãos mais lúcidos de sua capacidade criadora e transformadora na sociedade.

\section{REFERÊNCIAS}

Bacal, S. (2003). Lazer e o universo dos possíveis. São Paulo: Aleph.

Camargo, L. O. L. (2006). O que é lazer. 3. ed. São Paulo: Brasiliense.

Debortoli, J. A. O. (1999). Com olhos de crianças: A ludicidade como dimensão fundamental da construção da linguagem e da formação humana. Licere: Revista do Progra-ma de Pósgraduação Interdisciplinar em Estudos do lazer/UFMG. p.105-117. 
